\title{
Factors Affecting the Decision to Choose the Farmland Model in Le Tri Commune, Tri Ton District, An Giang Province
}

\author{
Y Thi Le ${ }^{a^{*}}$, Hieu Van Tran ${ }^{a}$ \\ ${ }^{a}$ Department of Rural Development and Natural Resources Management, Faculty of Agriculture and Natural \\ Resources, An Giang University, VNU-HCM, 18 Ung Van Khiem, Long Xuyen City, An Giang, 90000, Vietnam
}

\section{ARTICLE INFORMATION}

Article history:

Received: 15 October 2019

Revised: 20 November 2019

Accepted: 28 December 2019

\section{Keywords:}

Farmland model, sustainable farm, Khmer ethnic, upland irrigation

Correspondence:

*1ey31923@gmail.com

\begin{abstract}
A B S T R A C T
The study evaluated factors affecting the selection of agricultural farming models and advantages, difficulties, and opportunities in the implementation process to propose solutions to develop appropriate agricultural sustainable farming models. The study uses secondary and primary data through KIP interviews, focus group interviews, in-depth interviews, and farmer interviews. As a result, this study found education is an important factor affecting farmers in choosing their farming models and increasing agricultural production in their farmland. For most of the considered factors, the majority of Kinh people choose to evaluate the influence of the decision in choosing a farming model higher than another ethnic group (Khmer). Besides, the Khmer ethnic group accounts for a higher proportion of poor households (18.2\%) than the Kinh group. Because of low economic conditions, decisions on agricultural production of Khmer ethnic groups are less assertive than that of the Kinh people. On the other hand, there is a serious shortage of water in the dry season in the highlands, cultivated mainly by rainwater, ethnic minority accounts for $53.36 \%$ of the whole commune population, educational level makes it difficult to apply modern techniques in production. Therefore, strengthening and mobilizing people, investing in building upland irrigation systems, and using effective land conversion are essential activities to be carried out to improve the efficiency of farming models to make sustainable agricultural production that can increase income and enhance the economic life of local people.
\end{abstract}

\section{INTRODUCTION}

An Giang is a watershed province, one of the provinces with the most extensively cultivated land in the Mekong Delta. The total agricultural land area is 246,821 ha, of which paddy land accounts for more than $82 \%$. Tri Ton district is a mountainous district of An Giang province, of which ethnic minority people account for the majority of about $51 \%$ ), and the poverty rate accounts for $50 \%$ (An Giang Statistical Office, 2008). The study area of Le Tri Commune, Tri Ton District, An Giang Province is a halfmountain area, and gray soil is less nutritious than plain land of the province. Up to $24 \%$ of the population is Khmer. The total natural land area is 15,208 ha, of which 
agricultural land is 10,683 ha. Upper farmland depends on rainwater, so it is possible to grow only one crop of rice or a short-term crop per year. In comparison, lowland fields have irrigation systems from Vinh Tế and Tám Ngàn canals that can increase the rice intensity of farmland to twice cropping in a year. Some households may grow one rice crop and one short-term crop (vegetable) or three rice crops.

The majority of farming system is still monoculture of rice, low productivity, unstable rice prices, pest, and disease situation, making such economic difficulties to some households, especially the poor (Minh \& Xuan, 2007).

With the natural conditions and topography of the highlands, agricultural production in the Tri Ton district is strongly influenced by the water source used in cultivation. Severe water shortage during the dry season, the primary source of water is rainwater. On the other hand, the economy of the local people is mainly based on agricultural production. However, farmers here face many difficulties. Some environmental problems: stormwater runoff causes soil erosion or water shortage during the dry season. Other issues belong to the socioeconomic: transportation costs are high due to bad roads, poor households in the sloping land did not have access to the market well, and the policy of agriculture promotion and propaganda has not been adequate. Besides, the local people's intellectual levels relatively low, and the farming practices are backward, leading to low economic efficiency compared to the potential of agricultural production in the region (Khoa \& Duong, 2012).

Therefore, this study aims to assess the local farming models' status and identify resources, economic and social factors that may affect farmers in choosing their farming models in the study area.

The study pursues the following specific objective, are: (1) to explore the situation and advantages and difficulties in the agricultural production process in Le Tri commune, (2) to analyze factors affecting the choice of farming model in the above field, and (3) to compare the economic efficiency between models and proposing solutions to develop appropriate and sustainable agricultural farming models with conditions of the region in the future.

\section{RESEARCH METHODS}

\section{Selection of the study area}

This research was conducted in the Le Tri commune, Tri Ton district because Le Tri is a remote area of the Tri Ton district with complex mountainous terrain. Khmer community accounts for a high proportion of $53.36 \%$ of the commune's population. In general, farmers in the Le Tri commune still face many difficulties in agricultural production. The upper part of the region depends on rainwater. Therefore, people here have to adapt to selecting crop structure so the cropping system will meet the development project's goal in the study site (Statistical Yearbook, 2015).

\section{Methods for data collection}

\section{The secondary data collection}

Mainly collect and synthesize secondary data from various sources, including Scientific journals, the Internet about the economic efficiency of models, and the restructuring of agriculture production. This study collects and synthesizes secondary data from books, newspapers, and government policies related to rice farming in mountainous areas and the need to use irrigation water in agricultural cultivation and previous studies related to the research topic, crop restructuring, and socio-economic reports, agricultural production situation, statistical yearbooks of the study area.

\section{The primary data collection}

The methods used to collect primary data include interviews with key informant panel (KIP), in-depth interviews, household interviews with questionnaires, PRA tools (Participatory Rural Appraisal), Focus Group Discussion, and direct observation.

\section{Key informants and survey respondents}

Informants for KIP interviews are the extension officers at the study site to explore such issues as; the condition of agriculture production, the effectiveness of farming models, and the government policies and programs.

In-depth interviews have been conducted with farmers in Kihn and Khmer ethnic groups; two farmers from the Kihn group and two farmers from the Khmer group. The survey has selected 30 farm households using a simple random sampling. This study uses a structured questionnaire to interview those household survey 
respondents. Direct observation was also done to observe people's agricultural production and daily life activities in the area in recent years. A focused group discussion is done with farmers in those two ethnics to collect information at the community or group level.

\section{Methods of data processing and analysis}

For secondary data, this study synthesizes the relevant information to support the analysis of this study's issues. The primary data collected from KIP interviews, in-depth interviews, and focus group discussions are analyzed through a qualitative data analysis method.

Data obtained from farmers' questionnaires are processed and analyzed by descriptive statistical methods through Microsoft Excel 2010 and SPSS software to produce statistical results such as average, frequency, percentage to prove and argue for the topic.

\section{RESULTS AND DISCUSSION}

\section{Cultivation status in the study area}

Le Tri commune has a total natural land area of 2,669 ha, of which the size of agricultural production land accounts for 1,852 ha. In 2018, the commune's rice area was 1,638 ha. It consists of a crop area of $48 \mathrm{ha}$, a specialized land area of 70.69 ha, and an unused land of 75.35 ha. The population of the commune in 2016 is 5,860 people, with 2,990 people, or over $50.50 \%$ of the total population are Khmer ethnic. The current farming models include; (1) two rice crops and one vegetable crop (autumn-winter vegetables), and (2) two rice (winter-spring/summerautumn rice) and fruit trees. Breeding mainly cows, pigs and goats. There are 22 households raising fish of all kinds in the extensive form, with an area of ponds and lakes of about 2.85 ha. The estimated harvest output is about 23 tons. The source of income of farmers varies greatly over time. The average income per capita is 24,597 million VND/capita/year. For the most part, the people's economic life mainly relies on farming on small and fragmented fields and fields, accounting for about $70 \%$ of total income, while other income sources are less than $30 \%$ of them. Income from fruit trees and livestock tends to increase over time, and income from cheap labor, resource exploitation is gradually losing. The main production constraints of this region include: drought, market, unstable prices; High production costs (prices of materials, animal/seedlings, epidemics, high investment) and changes in the situation of "good harvest, devaluation" tend to be repeated, causing significant impacts on the lives of farmers and a part of poor rural people (Report to the People's Committee of Le Tri commune, 2018).

Table 1. Cultivate crops in the Le Tri Commune in 2017

\begin{tabular}{llll}
\hline Type tree & $\begin{array}{l}\text { Area } \\
\text { (ha) }\end{array}$ & $\begin{array}{l}\text { Productivity } \\
\text { (ton / ha) }\end{array}$ & $\begin{array}{l}\text { Output } \\
\text { (tons) }\end{array}$ \\
\hline $\begin{array}{l}\text { Winter-Spring } \\
\text { rice }\end{array}$ & 1364 & 5,5 & 7502 \\
$\begin{array}{l}\text { Summer-Autumn } \\
\text { Rice }\end{array}$ & 1652 & 5 & 8260 \\
$\begin{array}{l}\text { Cultivating the } \\
\text { third crop }\end{array}$ & 970 & 5 & 4850 \\
$\begin{array}{l}\text { Corn } \\
\begin{array}{l}\text { Assorted } \\
\text { vegetables } \\
\text { (cucumber, melon }\end{array}\end{array}$ & 124 & 12,5 & 680 \\
$\begin{array}{l}\text { is mainly) } \\
\begin{array}{l}\text { Cassava, potato of } \\
\text { all kinds }\end{array}\end{array}$ & 25 & 24 & 1550 \\
$\begin{array}{l}\text { Green beans, } \\
\text { beans of all kinds }\end{array}$ & 20 & 1,2 & 600 \\
\hline
\end{tabular}

Source: Statistical Yearbook, 2018

\section{Factors influencing decision making}

\section{Farmer resources}

The number of household heads in the age group $31-40$ and $51-60$ accounts for the highest proportion (30\%); In the age group of 41-50 years, the proportion is also quite

Table 2. Age, experience, ethnicity and demographic of household respondents

\begin{tabular}{llllll}
\hline Household group & Age (Year) & Experience (Year) & Ethnicity & Demographics \\
\cline { 4 - 5 } & & & Kinh (\%) & Khmer (\%) & (people) \\
\hline Rich & 39 & 20 & 15,8 & 9,1 & 2 \\
Medium & 30 & 17 & 84,2 & 72,7 & 4 \\
Poor & 53 & 12 & 0,0 & 18,2 & 3 \\
\hline
\end{tabular}


high $(26,7 \%)$ and the lowest rate $(3,3 \%)$ in the $20-30$ year. The old group has 1 to 10 years of agricultural production experience, 11-20 years, the proportion is also quite high $(33,33 \%)$. The average number of years of agricultural production experience of the household heads is high (16,33 years). The results in Table 2 show that the age of 39 and the rich households with 20 years of production experience are higher than the other two groups. However, the age group of the poor-headed households is the highest. The number of years of experience is lower because most of them are invalids, the illness they live mainly on their children's wages, children working far away from local authorities support.

This shows that the middle-aged and experienced groups are positively correlated with the level of product success and are the necessary basis for the boldness of introducing production models and applying early technical advances to invest in production effectively. In addition, according to Table 2, the average age of rich households is 39 , and the proportion of the age group from 31 to 40 accounts for the highest $30 \%$. This proves that the rich households under 40 years old account for the majority compared to the age of over 50 years.

According to the survey of the household, the percentage of household heads with primary education is 16 , accounting for $48,48 \%$, eight secondary education households accounting for $24,24 \%$, and a very low percentage of high school education, only $6,06 \%$ (see Table 3. While the percentage of illiterate households is quite high $12,12 \%$, the rest is $9,09 \%$ unknown because, in the interview, some household members answered on behalf of the household head, so they did not clearly remember the degree that his father had ever studied.

Table 3. Educational attainment of the household head

\begin{tabular}{lc}
\hline Academic level & Proportion $(\%)$ \\
\hline Illiteracy & 12.12 \\
Primary education & 48.48 \\
Secondary education & 24.24 \\
General education & 6.06 \\
Unclear & 9.09 \\
\hline
\end{tabular}

Thus, in general, the household head's educational level is only average and low, which makes it difficult for farmers to access new technological advances. Most of these household heads only work based on their own experiences, because according to parents learning to do things when their children are young, up to now, the head of household has about 20 - 30 years of experience depending on the age. In addition, they also gain more experience from people around them. Only a small number of people at the secondary and high school levels participate in local technical training workshops. Meanwhile, the head of the household is the decisionmaker to choose what models to cultivate.

However, based on the survey results, the number of eldest children in the family with a high level of education $(24,24 \%)$ attending secondary school (see Table 4.). The head of the household said that they are still trying and continuing to take care of children to go to school. They have to have a stable job to maintain the family income.

The percentage of people attending college or university accounts for more than $15 \%$, compared to the household head this level is much higher. It can be seen that this is a young, knowledgeable, and enthusiastic labor force that is a group of people who have good access to advanced science and technology in production to contribute to improving living standards, create a stable source of income for the family in the future.

Table 4. Educational attainment of family members

\begin{tabular}{lc}
\hline Academic level & Proportion $(\%)$ \\
\hline Illiteracy & 15.15 \\
Primary education & 21.21 \\
Secondary education & 24.24 \\
General education & 12.12 \\
Intermediate college & 6.06 \\
University / Postgraduate & 15.15 \\
Childhood & 6.06 \\
\hline
\end{tabular}

\section{Land resources}

The study results in Table 5 show the household with the highest agricultural land area is the upper field, with an average of $0,9 \mathrm{ha} /$ household. This data showed that the households' land resources are average, although this is the primary income source for families. Therefore, there is a need to invest in irrigation systems to serve irrigation water properly, so farmers can properly cultivate their land to get high production efficiency.

Table 5. Farmland area of household (ha/household)

\begin{tabular}{lcccl}
\hline Location & Average & Rich & Medium & Poor \\
\hline Mountainside & 0.40 & 0.4 & 0.30 & 0.500 \\
Upper field & 0.89 & 1.30 & 0.80 & 0.575 \\
Lowland & 0.86 & 1.18 & 0.83 & 0.575 \\
fields & & & & \\
\hline
\end{tabular}


For wealthy households, the farm's land area is over 1,3 ha, higher than those of the medium and poor households. Around $25 \%$ of rich households in the upper fields own the farmland of 1,1 to 2 ha/household. In comparison, about $75 \%$ of the middle and poor households cultivated the farmland area only from 0 - 1 ha/household (see Table 6.). In general, the richer, the wealthier the household is, the more it will facilitate economic development. However, the proportion of the cultivated land is only one-third of the average and poor households, so it is necessary to have technical measures, innovate and apply advanced production methods in order to contribute to improving and developing the efficiency of agricultural production models of the medium and poor households in the locality.

Table 6. The proportion of farmland in the upper field

\begin{tabular}{ll}
\hline Land Area (ha) & Proportion (\%) \\
\hline $0-1$ & 75 \\
$1.1-2$ & 25 \\
\hline
\end{tabular}

\section{Capital resources}

Capital is an essential element in all business activities, the daily life of people. The capital is crucial for the success of the production process. With enough capital, farmers can produce a successful farm-business and improve their life. However, according to the survey results, most households still lack or capital for their farming activities.

Most of the primary income of the people is from rice, livestock, and fruit trees. Some households without productive land work as hired laborers and earn hired labor. However, as paid laborers, their income is relatively low, and the number of working days is not stable. Most of the interviewed households said that they lacked capital for production. The number of borrowers accounting for $63,33 \%$ was among the medium and poor households, with 24 borrowing households accounting for $80 \%$ of the total 30 households (see Table 7.). Farming households usually buy agricultural needs from grocery stores by way of debt and repay them in the harvest season.

Table 7. Household capital

\begin{tabular}{lcc}
\hline Capital & $\begin{array}{c}\text { Quantity } \\
\text { (households) }\end{array}$ & $\begin{array}{c}\text { Proportion } \\
(\%)\end{array}$ \\
\hline Loan capital & 19 & 63.33 \\
Capital available & 11 & 36.67 \\
\hline
\end{tabular}

This study founds that poor household can access loans through the Farmers' Union in association with the Social Policy Bank. The amount borrowed from each household is from 10 - 30 million VND with an interest rate of 0 $0,65 \%$ with a payback period from 5 to 10 years to develop breeding and small business to improve income.

\section{Natural, economic, social conditions affect the farm model selection}

The survey results show that drought, markets, pests, and diseases are the most common consideration for the farm household in deciding their farming models. In particular, the drought element accounted for the highest proportion $(23,01 \%)$ with $13,42 \%$ Kinh and 9,59\% ethnic Khmer.

Currently, in Le Tri, nearly 200 hectares of agricultural land are affected by drought. If the drought persists, the water level of Tám Ngàn, Vình Tế, and Tri Ton canals decreased to $0,3-0,4 \mathrm{~m}$, and then it is expected that about 30 canals will be dehydrated serving production for 8.112 ha - Mr. Tri information. The risk of drought and saltwater intrusion in Tri Ton is enormous, especially when the mountains' temperature is higher than the plains, the heat is hot and prolonged, rarely rain.

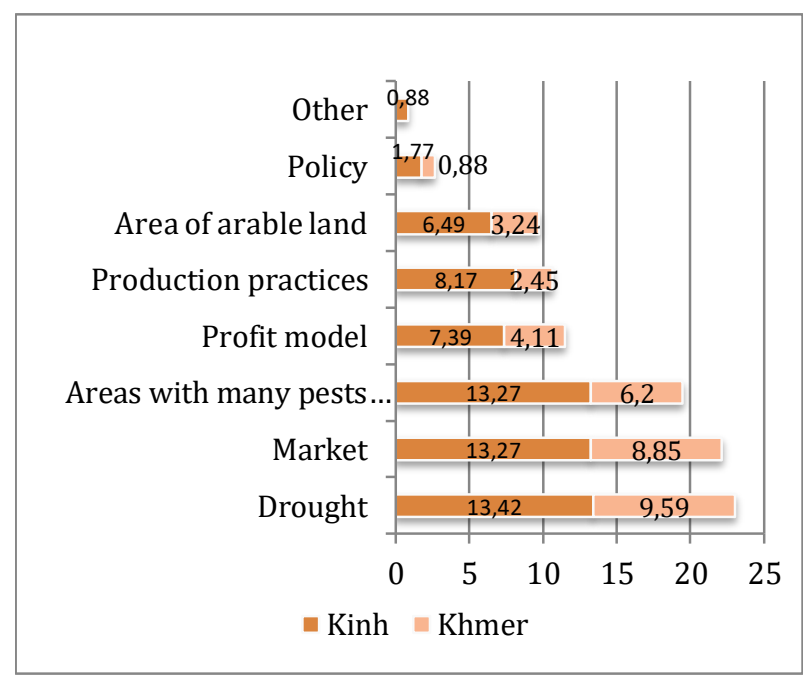

Figure 1. Percentage $(\%)$ of households identifying factors affecting the farming model

Regarding market factors, most people (Kinh and Khmer people) are concerned about the price, fearing not knowing who to do and who to sell, how to sell the product. And this is also a common problem of society. In recent years, agricultural products have been continuously facing market disadvantages, and unstable 
prices have significantly affected people's income and life.

In addition to the above factors, a small number of Kinh people also said that the increasing price of agricultural materials, unqualified pesticides and herbicides, and harmful rodents such as rats significantly impacted productivity and income. Therefore, when selecting farming models, farmers are also very interested in the quality of plant varieties such as suitable varieties, resistance to pests, drought tolerance, etc. This factor accounts for a small proportion of $0.88 \%$ of the total number of people selected.

The next is the area with many pests and diseases, accounting for $19 \%$ of people choosing between the Kinh and the Khmer ethnic groups respectively 13,21\%; 6,2\%, for the agricultural sector mainly rice and cash crops often have low productivity due to disease outbreak. In the last year, many cassava farmers died for almost no reason but only knew that the plants were sick and had no way to prevent or treat them.

Lowland areas of the 3-crop rice cultivation model also produce low yields, where people often sow unevenly, resulting in many diseases that are difficult to control. Currently, the private sector manages the state-owned irrigation pump system, so the "seasonal calendar" they will decide and control makes it difficult for local authorities to mobilize people to participate in the production organization batch. Seeding time between 2 groups of objects spaced 1 to 2 months apart from diseases, plants are also affected by insects and rats, causing heavy losses (Table 8).

Table 8. Seeding time for rice farming model in the Le Tri Commune

\begin{tabular}{llll}
\hline Type of & \multicolumn{3}{c}{ Seeding Time (Solar Calendar) } \\
\cline { 2 - 4 } $\begin{array}{l}\text { irrigation } \\
\text { systems }\end{array}$ & Winter & Summer- & Autumn \\
Spring & Autumn & Winter \\
\hline $\begin{array}{l}\text { Private } \\
\text { managed }\end{array}$ & September & May & January \\
$\begin{array}{l}\text { irrigation } \\
\text { pump system }\end{array}$ & - October & -June & February \\
Local & & & \\
government & November & March & $\begin{array}{l}\text { Season 3 } \\
\text { ran out of } \\
\end{array}$ \\
& & -April & water \\
\hline
\end{tabular}

This study has asked questions to the selected farmer group in order to identify factors affecting the household situation in the last five years. The information is then quantified through the levels of the scale from 1 (very low) to 5 (very high). Figure 2 presents the results of the influence of factors on the farming situation from the farmer's point of view, most criteria being assessed at a very high level of conformity. Based on Figure 9, 26 households identified that the drought factor is the most influential factor. Fifteen households $(57,69 \%)$ think the drought situation in water shortage in the dry season is high, 3,85\% of households rate this factor was very high, and three households felt that it did not affect much at the low level $(11,54 \%)$. Besides, market factors and areas where many pests and diseases appear are similarly analyzed. However, the number of people choosing to evaluate these two factors is approximately equal to 22; 25 households. At that time, both of these factors were considered by farmers to be the most influential at $76 \%$ and $68,18 \%$.

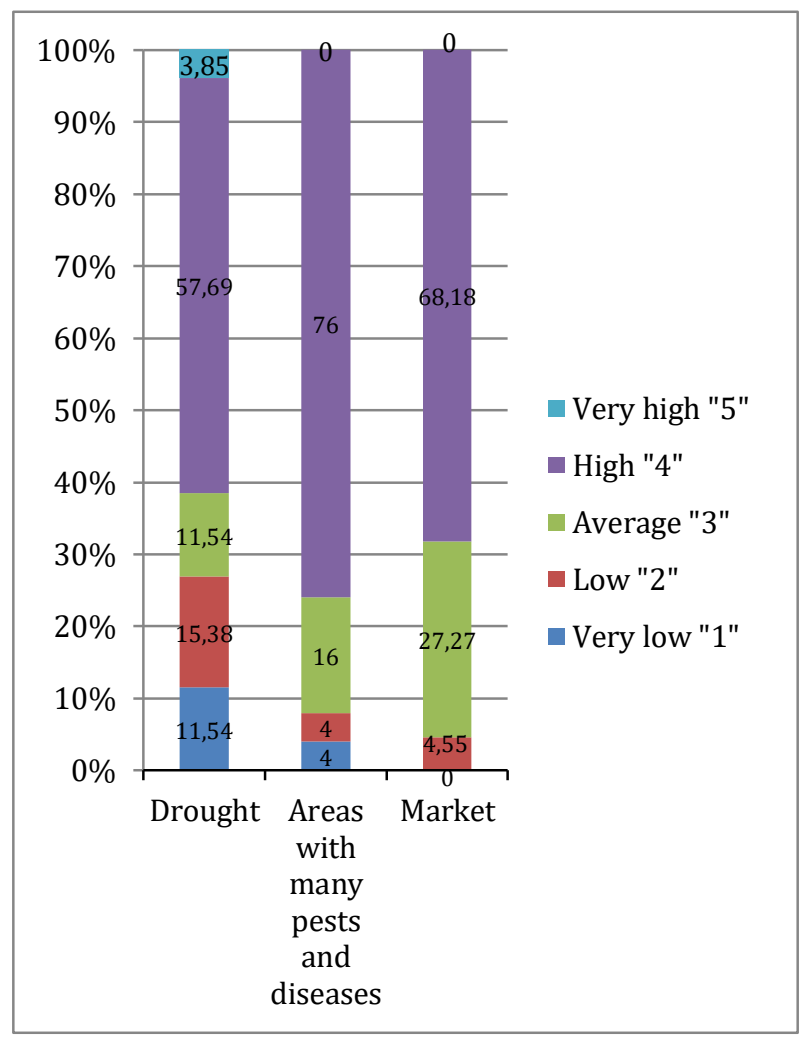

Figure 2. The level of factors affecting the farming model

Figure 3 shows that most Kinh people have a higher rate of evaluation of the factors than ethnic households. Up to $68.18 \%$ of the Kinh people think that market factors will affect the most compared to the other two factors because the prices of many agricultural products are low, 
changing constantly, the output is complex for most people after farming to find their own output, there are non-consumable backlog items. For ethnic minority groups, small and fragmented farming areas with low productivity will greatly affect the household's income. However, the revenue does not change much.

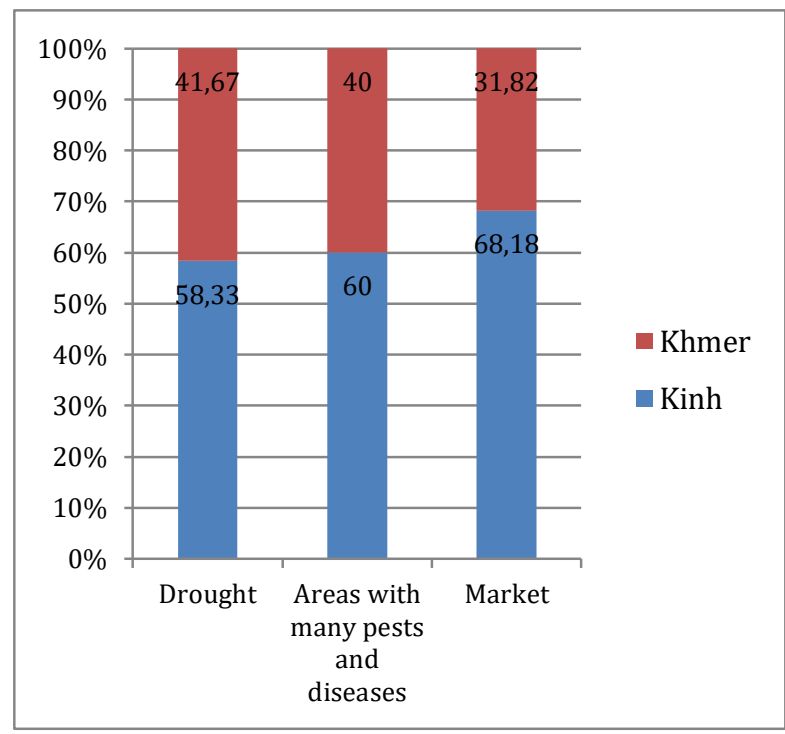

Figure 3. The proportion of ethnic groups assessing factors affecting the farming model

Therefore, market factors with households are less concerned than drought factors and disease outbreak areas. Khmer people think that when they want to switch to cultivating models for households, the water source is very important. Most of the upper land mainly depends on rainwater. Kinh people said that they need to build a reservoir for their farmland.

\section{The distribution of farming models by topography}

In the upper field, from 2000 until now, the natural water in the mountain no longer flows down, resulting in water shortage in the dry season. Therefore, from 2-season rice gradually transferred to 2 or 3-season corn. Some shifted cashew cultivation has moved to tầm vong for hilly land. At the same time, thanks to the policy of supporting loans from the policy bank, people started to develop cow raising. After harvesting the remaining corn stalks, people take advantage of the cows to feed so that the income begins to increase. However, by 2010 drought occurs around March - April of the lunar calendar, severe water shortage of dead rice, the lack of cow-eating grass is a risk due to the weather, so uncontrolled people have started shifting their rice land to orchards (mangoes).
People's income increased, but there was a shortage of family labor because most young workers had to migrate to make a living. Mechanization began to appear in 2014. During this period, severely affected corn plants reduced people's yields for unknown reasons. The number of households raising cattle also decreased because the market competed with the price of Australian cattle, but the price of breeding animals increased significantly, reducing people's income significantly because income from cattle raising accounted for 30-35\% of the economy extra in the family.

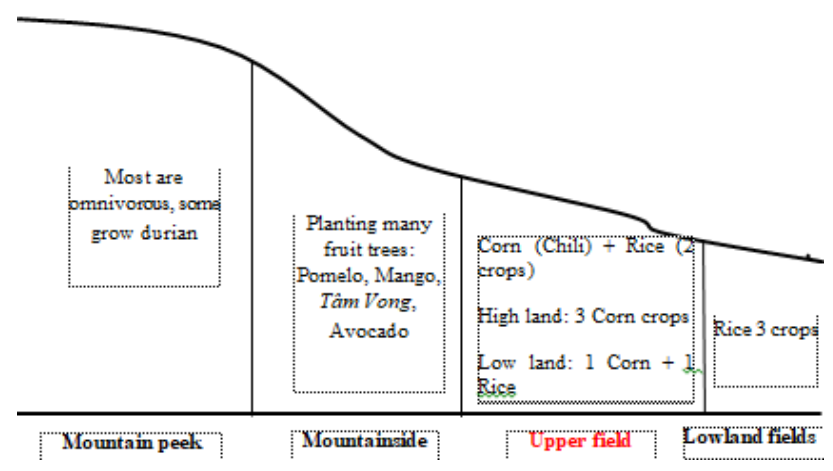

Figure 4. Topographical distribution of farming models

\section{Economic efficiency of each model}

There are three promising farming models in the studied area of Le Tri commune (fruit tree cultivation model, 02 rice crops and 02 rice, 01 vegetable crop.). Table 9 presents the results of the aggregate analysis in 2018 based on household interview data. The table shows the investment capital of the model of fruit trees, two-rice

Table 9. Average total revenue, total expenditure and profit of farming models in 2018

\begin{tabular}{lccc}
\hline Item / Model & Fruit tree & $\begin{array}{c}2 \text { rice } \\
\text { crops }\end{array}$ & $\begin{array}{c}2 \text { rice crops - } \\
\text { 1 vegetable } \\
\text { crop }\end{array}$ \\
\hline $\begin{array}{l}\text { Total } \\
\text { expenditure }\end{array}$ & 36,300 & 45,715 & 46,630 \\
Total revenue & 62,251 & 79,337 & 107,556 \\
Profit & 25,322 & 33,663 & 60,926 \\
Capital & 0,7 & 0,74 & 1,3 \\
$\begin{array}{l}\text { Total area } \\
\text { ha) }\end{array}$ & 8,9 & 12,2 & 11,45 \\
\hline Unit of calculation: $V N D ~ 1,000 / h a$ &
\end{tabular}


crops, and two-rice and one vegetable crop in ascending order. When investment capital increases, so do the total revenue and profit capital increases, so do the total revenue and profit. This shows that investment capital is very important in developing the above farming models and positively correlates with profits. The two models with the highest profit are the two-rice and one vegetable crop (60 million VND/ha/year) and the two-rice crops (33 million VND/ha/year). Besides, the two-rice and one vegetable crop still produce the highest profitability ratio when it comes to capital efficiency. This results in the highest capital efficiency when investing in this model. According to the farmer's assessment, income from rice production in the rice farming model is very low compared to income from vegetable crops. But the ecological benefits are huge because the rotation of the crop will limit the pathogens and improve the soil's nutrition, thus increasing the effectiveness of the model.

Table 10 also shows that the average area of the models varies. Farmers usually prioritize rice production, and in recent years a few farmers have turned to grow fruit trees, mainly mangoes. The new conversion is not stable, so people have not yet confirmed the economic efficiency of mango. However, fruit trees have a relatively high life expectancy of 5 - 10 years with some trees longer than that, so once stable, the fruit tree model's profit will bring a lot.

\section{Household income}

Farm production activities in the commune include agricultural production (rice, etc.), orchard gardening, animal husbandry, and other non-agricultural activities. Table 10 presents the total net income from the main activities of households in 2018. The average net income of each household is VND 41.45 million per year. When looking at each model, the income of two-rice and one vegetable crop is highest (67.9 million VND/household/year), followed by fruit trees (58.6 million VND) and livestock (39.2 million VND). Besides, households can also earn additional income from other non-agricultural activities such as grocery trading, catering services, agricultural supplies, agricultural irrigation services, etc. This activity contributes an additional 9.6 million VND/household/year on average per household.
Table 10. Total net income from farm activities in 2018

\begin{tabular}{lc}
\hline Item & Average \\
\hline 2 rice crops & 31,885 \\
2 rice crops, 1 vegetable crop & 67,900 \\
Fruit tree & 58,644 \\
Breed & 39,207 \\
Nonagricultural & 9,600 \\
\hline Total & 41,45 \\
\hline Unit of calculation: VND 1,000 / household
\end{tabular}

\section{Identify the effectiveness of the model}

In terms of economic aspects, the model of two rice crops and one vegetable crop and fruit trees brings the highest economic efficiency. However, the two-rice crops and one vegetable crop require a lot of labor, skilled professional labor (experience in growing crops). Therefore, this farming system is usually only applied to households with good conditions, labor and experience, and small land areas. Besides, the application of rice vegetable combination models are also affected by the market while the prices of crops are volatile and precarious. The fruit tree model is much developed in the upland and mountainous areas, which requires farmers to have good conditions in terms of capital and land area. Prices of fruit trees are also relatively stable compared to rice and crops. However, if immediately encountered adverse weather or heavy rain will also affect crop yields. Lack of water, trees will grow slowly with little fruit, yield decreases so households with large planting areas will actively build reservoirs containing separate water for irrigation in the dry season.

For the livestock model, the profit is quite good. However, in recent years, animal husbandry's price has continuously increased, the market is very competitive compared to Australian cattle. As a result, the number of farmers decreases while still raising retain breeds with children aged 15-20 years. As for the 2-crops rice model, although the profit is low but easy to apply, it is a traditional model and the first choice for farmers in their production. However, this time the price of fertilizer supplies, pesticides, labor increased, leading to low production profits. 
From an environmental perspective, the fruit tree model minimizes environmental pollution by using less fertilizer and does not need to burn copper, and is afraid of organic pollution before treating straw thatch. In general, the economic efficiency of farming models varies by topography and elevation. This is due to various causes, irrigation systems, market prices, investments, and each farming model's resources.

\section{CONCLUSIONS}

Le Tri is a commune with great potential for agricultural production, especially two-rice crops and one vegetable crop. People have a lot of knowledge and experience in production, although the household head's educational level who decides on the farming model is still low. On average, each household has an arable land area of 0.9 ha/household and the average yield of the following farming models: Rice (5 tons/ha), corn (17 tons/ha), beans green, and beans of all kinds (1.2 tons/ha), for fruit trees model ranges from 4-5 tons/ha. However, due to most people being converted, the unstable productivity mainly contributes to income for each day or each harvest period. When considering investment costs, it is found that investment capital is very important for developing a farming model and positively correlating with profits. Investment costs between the models increased as follows: Fruit trees, two rice crops, and two-rice crops with one vegetable crop. For two-rice crops and one vegetable crop, rice income is very low compared to income from the vegetable.

The selection of farming models is influenced mainly by natural, economic, and social conditions, in which drought, market, and pests and diseases are most affected. Besides, the household head's low educational attainment makes it difficult to access and apply scientific and technological advances to production. With lack of water in the dry season, unsatisfactory seeding leading to pests and diseases develop, these cause a lot of damage. Therefore, farmers have based on the farming area's specific characteristics to choose suitable and effective farming models such as two rice crops and one vegetable crop, and fruit trees. In addition, local authorities have also mobilized people to organize production, mass seed, use quality seeds, continue to invest and improve irrigation systems. Thereby, it can be seen that to improve people's lives, the local government and the people need to have a coordination with each other. The level of government needs to link people with agencies and businesses. In addition, as managers, enterprises create favorable conditions for people, and people comply with and actively present their desires and solutions to contribute to the highland economy's development.

\section{ACKNOWLEDGMENT}

We would like to thanks the staff in Le Tri Commune, Tri Ton District, and farmers in Le Tri who have enthusiastically cooperated to share valuable information and experiences.

\section{REFERENCES}

Can, N. D., \& Vromant, N. (2006). Mekong Delta Development Research Institute, Can Tho University.

Center for research - consultancy of social work and community development. (2007). PRA Tool Participatory rural assessment method. . Ho Chi Minh City.

Khoa, L. V., \& Duong, N. T. (2012). The situation of cultivation and production potential of weathered land in Tri Ton district, An Giang province. Journal of Science, 78-86.

Minh, N. V., \& Xuan, V. T. (2007). Building a model of sustainable farming systems in crop restructuring in high sandy land in the seven mountains of An Giang. Journal of Science 2007: 8, 57-66.

Report to the People's Committee of Le Tri commune. (2018). Report on socio-economic implementation situation in 2018 and directions and tasks for socio-economic development in 2019.

Statistical Yearbook. (2015). People's Committee of Le Tri commune.

Tai, D. A. (2008). Curriculum analysis statistics. Hanoi: Statistical Publishing House. 